\title{
OBJETOS DE APARECER E DE DESAPARE- CER DE ANASTACIA: DIÁLOGOS SOBRE PASSABILIDADE TRANS* E O DIREITO AO MANEJO DOS PRÓPRIOS DADOS ON-LINE A PARTIR DE UM ESTUDO DE CASO
}

SÉRGIO RODRIGO DA SILVA FERREIRA UNIVERSIDADE FEDERAL DA BAHIA SALVADOR, BAHIA, BRASIL SERGIORODRIGOSF@GMAIL.COM

LEONOR GRACIELA NATANSOHN UNIVERSIDADE FEDERAL DA BAHIA

SALVADOR, BAHIA, BRASIL GRACIELA71@GMAIL.COM 


\section{OBJETOS DE APARECER E DE DESAPARECER DE ANASTACIA: DI-} Álogos SOBRE PASSABILIDADE TRANS* E O DIREITO AO MANEJO DOS PRÓPRIOS DADOS ON-LINE A PARTIR DE UM ESTUDO DE

\section{CASO}

Resumo: A partir do relato de uma mulher trans* se articulam diálogos acerca da privacidade on-line e as questões trans*, a passabilidade e a autodeterminação nos espaços mediatizados, evidenciando as implicações das tecnologias digitais na produção subjetiva. Chega-se assim a ações de desindexação no entendimento da copropriedade da informação e da cogestão dos limites da privacidade.

Palavras chave: Transexualidade; Passabilidade; Privacidade; Comunicação digital.

\section{OBJETOS DE APARECER Y DESAPARECER DE ANASTACIA: DIÁlO- GOS SOBRE PASABILIDAD TRANS* Y EL DERECHO AL MANEJO DE LOS PROPIOS DATOS EN LÍNEA A PARTIR DE UN ESTUDIO DE CASO} Resumen: A partir del relato de una mujer trans* se articulan diálogos acerca de la privacidad en línea y las cuestiones trans *, la pasabilidad y la autodeterminación en los espacios mediáticos, evidenciando las implicaciones de las tecnologías digitales en la producción subjetiva. Se llega así a acciones de desindexación en el entendimiento de la copropiedad de la información y de la cogestión de los límites de la privacidad.

Palabras clave: Transexualidad; Pasabilidad; Privacidad; Comunicación digital.

ANASTACIA'S OBJECTS OF APPEARING AND DISAPPEARING: DIALOGUES ON TRANS* PASSING AND THE RIGHT TO THE MANAGEMENT OF THE OWN DATA ONLINE FROM A CASE STUDY

Abstract: We perform with a trans* woman's narrative to articulating dialogues about online privacy and trans* issues, passing and self-determination in mediated spaces, highlighting the implications of digital technologies for subjective production. This leads to actions of de-indexing in the understanding of co-ownership of information and co-management of privacy limits. Keywords: Transsexuality; passing; Privacy; Digital communication. 


\section{INTRODUÇÃO}

Ao nos propormos a pensar a relação de produção subjetiva em ambientes digitais enquanto processos de digitalização de si - entendidos como constituição de si no processo de converter-se em dados digitais (FERREIRA, NATANSOHN, 2018) - é que temos debatido a questão das vivências trans* interseccionalizando suas marcas de diferença de gênero e aspectos culturais territoriais. Durante o V Seminário Internacional Enlaçando Sexualidades, ocorrido em Salvador, em setembro de 2017, apresentamos o caso de Anastacia (FERREIRA, 2017), um caso muito específico e de difícil acesso em se tratando de estratégias de vivências trans* (o que justifica a escolha do método Estudo de (aso).conforme apresentaremos a seguir.

O tema deste artigo são as estratégias de digitalização de si e de relacionamento em ambientes digitais focando em questões de gênero que envolvem pessoas trans*. Aqui, apresentaremos modos em que efeitos de verdade sobre gênero, transexualidade e dispositivos digitais atravessam a vivência de uma pessoa trans* e agencia suas relações e suas ações on-line. A questão que trazemos é: como sujeitos trans podem manejar seus dados nas redes sociais, incluindo a possibilidade de apagar elementos de seu passado? Quais são os atores envolvidos? De que modo esse deletar-se se relaciona com o conceito de passabilidade cisgênera? Objetiva-se, assim, descrever ações para se constituir enquanto sujeito trans* e para gerenciar dados para relacionar-se com a identidade de gênero assumida on-line em processo de indexação e desindexação.

Adotamos aqui a o uso do asterisco $\left({ }^{*}\right)$ depois do termo trans como parte do ativismo de pessoas trans* tem feito atualmente. Essa estratégia serve para transformar a palavra em um termo guarda-chuva que engloba todas as nuances identitárias e de identificações trans*, uma vez que o

termo trans pode ser a abreviação de várias palavras que expressam diferentes identidades, como transexual ou transgênero, ou até mesmo travesti. Por isso, para evitar classificações que correm o risco de serem excludentes o asterisco é adicionado ao final da palavra transformando o termo trans em um termo guarda-chuva [umbrella term] - um termo englobador que estaria incluindo qualquer identidade trans "embaixo do guarda-chuva”. Daí a ideia do guarda-chuva. Além disso, o termo também pode incluir pes- 
soas trans* que se identificam dentro e/ou fora do sistema normativo binário de gênero, ou seja, da ideia normativa que temos de "masculino" e "feminino" que forma um binário (KAAS, 2013, on-line).

A história deste artigo começa quando, em 2014, Anastacia (adotamos um nome fictício a pedido e cocriado com a entrevistada) me contatou pelo seu novo perfil do Facebook (após excluir o anterior) pedindo para que eu apagasse todos os textos, fotos e vídeos em várias plataformas digitais que faziam referência a ela nos quais ainda era vista como um menino. Conheci Anastacia antes do início de sua transição, ela era um rapaz andrógino, e aos poucos foi constituindo seu corpo e sua subjetividade feminina. Pude acompanhar esse processo dando-lhe algum suporte enquanto amigo. Entretanto, como no caso de muitos sujeitos trans*, Anastacia não recebeu apoio da família e sofreu com o rechaço social de pessoas que a conheciam antes dos procedimentos de transição. Por isso, mudou-se para uma cidadezinha do interior, casou-se com um rapaz de lá (em coabitação) e passou a viver como uma mulher cisgênera (em oposição a pessoas trans*, cisgêneros são aquelas pessoas que se identificam com a designação de gênero que lhes foi dada ao nascer, também chamadas simplesmente de cis).

Portanto, este trabalho se justifica em parte pelas implicações de relações interpessoais com sujeitos trans* e o processo de pesquisa do autor. A atitude de Anastacia se justifica se levarmos em conta que pessoas trans* são extremamente vulneráveis à violência no Brasil, e que somos hoje o país do mundo que mais mata pessoas trans* em números absolutos. Conforme relatório da Rede Trans Brasil (REDE, 2018), só no ano de 2018, 150 pessoas trans* foram mortas por transfobia no país, sendo esses números especialmente alarmantes por serem, devido especificidades do tipo de crime, subnotificados.

Minha relação com Anastacia é profundamente atravessada pela Internet. Conhecemo-nos quando eu procurava um companheiro ou companheira para um blog sobre questões LGBT. Durante cinco anos mantivemos esse projeto, com uma produção regular de conteúdo local sobre as questões de gênero e sexualidade na Grande Vitória, na capital do Espírito Santo. Esse trabalho nos aproximou muito e logo nos tornamos amigos. Saíamos juntos sempre para boates e bares, gay friendly ou não. Ela frequentava minha casa regularmente, em churrasco e pousando, e participávamos também juntos 
de um grupo acadêmico de militância LGBT na Universidade Federal do Espírito Santo (UFES).

$\mathrm{Na}$ época, antes de se assumir uma mulher trans, ela cursava uma graduação na área das biomédicas e sua identidade andrógina - de não identificação com nenhum dos gêneros - era sustentada por uma questão de déficit hormonal, afirmando-se nem como homem, nem como mulher, o que com seu humor irônico era alvo de deboche, inclusive sobre a relação de gênero entre seus amigos. Lembro perfeitamente quando confessou-me ainda um pouco insegura, enquanto caminhávamos pelo campo da UFES conversando, que estava começando a tomar hormônios. Minha pergunta foi se ela havia se descoberto enquanto mulher trans - o que negava todo um discurso que fazia sobre si mesma até então de se colocar no entre-lugar do binarismo de gênero. A princípio ela negou, disse apenas que estava se experimentando, que não possuía respostas. Descreveu-me com animação a sensação de estar como uma mulher púbere, falou das mudanças repentinas de humor e me mostrou o proto-seio que escondia sobre um casaco mesmo num dia quente na capital capixaba além de descrever as dores que sentia enquanto eles cresciam. O grupo de pesquisa ao qual fazíamos parte tinha acabado de ler e discutir alguns textos da teórica queer brasileira Guacira Lopes Louro e Anastacia se sentiu bastante mexida com as reflexões da autora, a qual chamava intimamente de Guacirão. Nem dois meses depois, Anastacia se assumiria como uma mulher trans.

Éramos companheiros frequentes nos ambientes on-line e off-line, por isso assustou a mim e a nossos amigos em comum quando Anastacia sumiu completamente logo após se assumir. Os escassos contatos que conseguíamos ter com ela eram mensagens vagas e curtas que diziam coisas como “estou bem, mas preciso desaparecer por um tempo". Ela é querida por muitas pessoas e logo uma rede de amigos se formou para tentar conseguir informações sobre ela. Soubemos então que não fora aceita pela família e buscou outros conhecidos num distrito de uma cidade do interior com pouco mais de 4 mil habitantes. Lá se casou com um rapaz local e passou a viver como dona de casa. Pedia respeito aos amigos pela sua decisão, da qual se dizia consciente e tranquila.

Não sei quão violento foi quando alguns amigos foram pessoalmente atrás dela nessa cidade do interior para saber se estava realmente bem e se aquelas informações que chegavam pelas mensagens on-line eram verdadeiras. Confirmou-se, com a ida de alguns conhecidos em comum a vera- 
cidade de tudo que era dito, inclusive a necessidade de que fosse deixada em paz. Três anos após esse fato, Anastacia em nossa conversa falou da importância e motivação para ela daquele desaparecimento, para ela era importante desaparecer enquanto pessoa andrógena e reaparecer já "refeita" como mulher:

É um processo, como o nome já diz e, portanto, as relações mudaram durante ele. Inicialmente a androginia inerente à minha aparência desde sempre foi algo que me destoava da sociedade e me alijava dela, afinal, a curiosidade não causa sempre a vontade de entender, mas também a de temer, coisificar. Durante a transição veio a objetificação, advinda dos homens, muitíssimo presente nesse período, uma horda de homens interessados em ver um corpo adulto se comportando como o corpo de uma garota adolescente (crescimento dos seios, mudança do corpo no geral), mais uma vez a curiosidade masculina me coisificava e me transformava naquela criatura efêmera que todos queriam tocar, cheirar, penetrar, porém apenas fisicamente.

Quando a transição terminou, mais ou menos uns 6 ou 7 anos de processo (já não me recordo mais), no qual 2 deles permaneci em isolamento total (com ênfase no total, vivi mesmo numa espécie de cativeiro intencional, sequer botava o lixo para fora de casa) aí sim eu me inseri na sociedade como uma mulher cisgênera e, com isso, todas as questões feministas me perpassaram, cortando a carne, com muita velocidade e muita potência. É um processo longo, doloroso, mas hoje me sinto recompensada devido a tão criticada passabilidade, que é o alicerce da paz que hoje eu tenho com meu corpo e mente, vivendo em sociedade, sendo finalmente parte dela (desconsiderando, é claro, todas as questões do gênero feminino, que me afetam, como maternidade compulsória, relacionamentos abusivos e misoginia) (ANASTACIA, 2017, p. 3).

Esta pesquisa surge a partir de conversas exploratórias com a vivência trans* de Anastacia e com alguns textos dos estudos trans* acerca da questão da passabilidade ("to pass", em inglês) (STRYKE, 2015, LAMAS, 2014, DUQUE, 2017). A passabilidade (de "passar por”) é a característica de sujeitos trans* passarem por sujeitos cisgêneros, conseguindo apagar marcas do gênero imposto ao seu nascimento e de inocularem em si características do 
gênero com o qual se identificam e desejam ser reconhecidos, lidos como. Passar, desse modo, na perspectiva do gênero, diz respeito àquela pessoa que é percebida pelo gênero que deseja ser lida. Essa é uma ação que aponta para produção social do gênero quando tais sujeitos trabalham sua imagem, sua gestualidade, as inflexões de fala, modos de agir e se apresentar, - através de hormônios, próteses, cirurgias, práticas de atividade física, cortes de cabelo, uso de maquiagem, etc. -, ou seja, uma série de elementos culturalmente dados que imputam marcadores de gênero a um corpo.

Esta escrita preliminar é, ainda, parte dos enredamentos da tese de doutorado realizada junto ao Programa de Pós-graduação em Comunicação e Cultura Contemporâneas da Universidade Federal da Bahia. Ela se constitui no contexto em que ambientes digitais têm possibilitado processos de produção subjetiva e de relacionamento, e potencializado experimentações corporais e performatividades de gênero. Justifica-se este trabalho, ainda, pela importância de se fazer intercruzamentos das questões acerca da constituição da subjetividade e suas implicações com os dispositivos comunicacionais das tecnologias de informação e comunicação no mundo contemporâneo.

Este é um trabalho de conversas compartilhadas (HARAWAY, 1995) e se constitui, primeiramente, pela discussão de conceitos acerca da digitalização de si nas redes, negociações e copropriedade dos limites da interação, o manejo dos dados e os rastros digitais; e, posteriormente, pela articulação desses conceitos com aspectos das experiências vividas por uma mulher trans* adquiridas por meio de entrevista. Anastacia é uma interlocutora privilegiada quando entendemos "interlocutora" como "aquela que intervém no debate" de algum assunto (do latim interloqui) e seu privilégio sobre a temática, como o de quem experimenta uma situação da vida humana muito própria e de difícil acesso por sua própria natureza, uma situação que mobiliza questões sobre vigilância e sobre interseccionalidades das experiências trans*.

A coleta de dados considera a vivência que eu e Anastacia tivemos em comum, mas é especialmente através de uma entrevista com questões semiestruturadas sobre a atuação das plataformas de redes sociais feita por messageiro instantâneo on-line que caracterizamos as questões mobilizadas por este trabalho. Procurou-se nessa entrevista compreender hábitos de consumo de informação on-line de pessoas trans*, como contribuem com a transição, quais tipos de informação são trocadas e quais relações 
são estabelecidas. Em seguida, perguntou-se sobre a percepção da passabilidade e o manejo dos dados on-line e o impacto dessas ações nas relações e no processo de transição.

\section{DIGITALIZAÇÃO DE SI E COMPARTILHAMENTO DE SABERES TRANS* EM AMBIENTES DIGITAIS}

Lucas (Raquel) Platero (2014) afirma que as tecnologias de comunicação digital estão tornando a informação cada vez mais acessível para cidadania, em processos que estão transformando as relações. O autor destaca que para pessoas trans* e seus familiares essas tecnologias também Ihes possibilitam encontrar espaços para compartilharem suas vivências e debaterem importantes questões como autorrepresentação e pensarem-se a si mesmos muitas vezes em processos de autoimplicação ou de exposição de aspectos de si. Platero aponta como exemplo vídeos produzidos e divulgados por jovens contando os efeitos do uso de hormônios sobre seus corpos e de suas relações com familiares e amigos. Há também produções de pessoas trans* adultas em uma multiplicidade de blogs, sites e fóruns aconselhando sobre o cotidiano, dialogando, e trocando informações e experiências.

A digitalização de si pode ser definida como um processo de comunicação em que um sujeito compartilha informações pessoais com o outro ou com outros. Esse processo é essencial para a formação e manutenção de relacionamento, uma vez que o aumento das divulgações entre parceiros relacionais leva ao aumento da proximidade e a criação de laços (VITAK; KIM, 2014).

Com o aumento e a crescente popularidade das plataformas de redes sociais, as práticas de divulgação mudaram de maneira importante, principalmente pelo fato de que os usuários desses sites, geralmente, fazem essas divulgações de aspectos de sua vida para um público mais amplo, em vez de em pequenos grupos ou relacionamentos interpessoais.

Além disso, esses sites contêm uma série de características, tais como visibilidade, capacidade de edição e persistência de conteúdo e associação de conexões, que formam interações e comportamentos de divulgação específicos. Tais conteúdos publicados possuem persistência na rede, replicabilidade, escalabilidade e buscabilidade, bem como uma dinâmica com audiência invisível, contextos colapsados e a fluidez entre o público e o privado (BOYD, 2011). Esses fatores têm implicações significativas para teorias de comunicação relacionadas à digitalização de si e manutenção de relacio- 
namento (VITAK; KIM, 2014).

Anastacia (2017), a mulher trans* que conversamos, destaca a importância de trocas de informações em comunidades virtuais (em detrimento a outros sites e blogs) com a exposição e publicização da vivência de sujeitos trans* para se informar sobre hormonização, resultados esperados e efeitos colaterais. Ela afirma que ainda adolescente retirava as informações da plataforma de rede social Orkut.com: "todas as informações de dosagens iniciais, resultados esperados, fotos, relatos, eram retirados dali" (p.1). Já nessa época afirma que experimentou a automedicação: "Comecei roubando uns comprimidos de "Espironolactona" do meu pai (que teve um infarto e tomava este remédio, que em altas doses bloqueia a testosterona) $e$ outros de anticoncepcional da minha mãe" (p.1). Anticoncepcionais possuem uma quantidade de hormônios sintéticos que são usados por mulheres trans para desenvolverem em seus corpos características corporais consideradas femininas, como seios e quadris. Posteriormente, já adulta, quando decidiu pela transição, Anastacia procurou a mesma comunidade pelo Facebook: "De lá tirei tudo que pude de informação sobre o assunto, remédios, toda a questão social, de preconceito, o conceito de "passabilidade" e o porquê de buscá-lo, tudo" (p.1).

A vivência de Anastacia aponta para uma produção de saberes no ambiente digital que acontece com o compartilhamento e a soma das experiências dos sujeitos envolvidos e interessados na produção de um arcabouço de informação em circuitos alternativos aos tradicionais saberes psi e médicos que são constituídos em enredamentos on-line. "A comunidade 'Hormônios para Transexuais' realmente era onde eu via o que outras meninas estavam usando e o que estava acontecendo com o corpo delas ao usar cada substância ou mistura de substâncias" (ANASTACIA, 2017, p. 1).

Nesse sentido, os processos de digitalização de si que documentam os efeitos dos hormônios e outras intervenções no corpo eram, para Anastacia, fundamentais para o acesso a informações de interesse e revelavam evidências do que a experiência do corpo vivido que se autoexperimenta produz. "Na própria comunidade todas sempre postavam fotos de resultados, se informavam e passavam entre si o que era "bom" e o que não era bom para o resultado desejado. Meninas, moças e senhoras de todas as idades" (ANASTACIA, 2017, p.1).

Como um processo de regulação de fronteira pelo qual uma pessoa gerencia o acesso dos outros às informações pessoais, os sujeitos controlam 
até certo limite a informação manipulando a profundidade, quantidade de dados e frequência das exposições de si (DERLEGA; CHAIKIN, 1977, PETRONIO, 2002). A partir disso, os sujeitos podem renunciar livremente a sua privacidade quando eles têm um objetivo específico associado à sua digitalização de si, tais como aumentar o nível de intimidade com seus pares para construir relacionamentos, criar uma impressão desejada, conseguir aprovação social e receber apoio e afetos dos outros, compartilhar experiências para produção de saberes de interesse mútuo ajudando os indivíduos a construir suas próprias subjetividades e formular ideias e, por fim, aliviar o sofrimento através do processo de catarse, em que os indivíduos são capazes de liberar emoções compartilhando experiências ruins e medos (VITAK; KIM, 2014).

Nessas interações mediadas pelas mídias sociais narradas por Anastacia, o registro detalhado desse repertório passa a ser o modelo, com cópias nas memórias digitais dos aparelhos e das plataformas, e não apenas na memória dos participantes. Como todo processo de digitalização de si, há nas relações de trocas nas comunidades virtuais negociações de limites que garantem uma suposta proteção a intimidade de seus membros internos (inclusive negando o acesso a sujeitos não-trans*) e, por isso mesmo, uma copropriedade e responsabilidade sobre essas informações.

Trabalhamos com o conceito de copropriedade e limites negociados da privacidade nesses contextos a partir de trabalho de Sandra Petronio (2002). Para a autora o próprio entendimento de privacidade é o de um sentimento de que alguém pode se apropriar de algumas informações particulares do sujeito, marcando assim limites que delineiam a propriedade dos indivíduos sobre determinadas informação. Para Petronio, esses limites pessoais são gerenciados com o manejo das informações pessoais sobre si nas relações. Nessas comunidades digitais há a criação da ideia de espaços seguros em que tecnicamente é possível haver algum controle da audiência para a qual se expõe, ainda que haja riscos de vazamentos.

Nas palavras de Anastacia, essas comunidades em que pessoas compartilhavam de modo confidencial seus consumos de medicamentos e apresentavam as alterações corporais correspondentes com outras pessoas que possuíam questões em comum é o que motivou a escolha por se informar nesse espaço justamente por proporcionar um sentimento de segurança: "a comunidade citada foi a verdadeira enciclopédia que eu encontrei ao meu alcance no momento, alguns blogs existiam, porém sempre muito du- 
vidosos e cheios de listas enormes de coqueteis de comprimidos perigosos" (ANASTACIA, 2017, p. 1)

\section{PASSABILIDADE, DESINDEXAÇÃO E MANEJO DE DADOS}

Mas se por um lado os ambientes digitais permitem o fortalecimento de redes de saberes trans* on-line, por outro eles também são riscos devido à vulnerabilidade dos sujeitos envolvidos e do fato dos dados digitais que geram dar a eles pouca possibilidade de manejo uma vez que existe uma copropriedade de tais dados com os outros usuários da rede e da própria plataforma que dá suporte às redes sociais (como o Facebook, neste caso). Isso é especialmente problemático no que se entende enquanto processo de passabilidade, pois justamente esses rastros são evidencias muitas vezes desconfortáveis do passado desses sujeitos dos momentos em que eles viviam com o gênero ao qual lhes foi designado compulsoriamente ao nascer e que não contemplavam seu gênero de identificação.

Os processos de passabilidade apontam para a prática performática do gênero e expõem entendimentos do que é tido como norma em ser homem ou ser mulher nas sociedades, nos próprios atributos que são recorridos para se alcançar tal condição. Para Tiago Duque,

a experiência de passar por ocorre quando se performatiza uma suposta continuidade entre sexo, gênero e desejo; isto é, quando a heterossexualidade este em sua plena performance de inteligibilidade. Então a questão do passar por traz à tona o quanto, não só o gênero, mas a própria heterossexualidade é performática (DUQUE, 2017, p. 39, grifo do autor).

Hoje existem os discursos fortemente defendidos dos movimentos trans* que pleiteiam outros modos de se (re)(a)presentar. Sandy Stone (2015) questiona a ideia de que as pessoas transexuais devem desaparecer como tais para passar despercebidas como mulheres e homens cis. Para a autora é impossível lançar um contradiscurso que seja capaz de dizer verdades aos poderes médico-legais sobre os prejuízos sociais que tanto limitam a vida dos sujeitos trans*, se esses sujeitos estão programados a desaparecer. Para Stone, ao invés disso, as pessoas trans* deveriam sair e intervir criticamente na construção do que significa transexualidade. Como Leslie Feinberg, Stone entende que a luta trans* é resignificar o gênero e mostrar 
que ele possui um espectro que inclui muitos tipos de minorias de gênero e que todas elas necessitam unir-se para combater os discursos e práticas do heteropatriarcado capitalista (STRYKE, 2015).

Entretanto num contexto de violência e estigmatização transfóbica como em muitos locais do Brasil passar por pessoa cisgênera apresenta-se como estratégia de sobrevivência para sujeitos trans*. Se, como conceitua Marta Lamas (2014), gênero é a maneira pela qual as sociedades simbolizam a diferença anatômica dos corpos, nessa lógica cultural atua como força subjacente da desigualdade de tratamento entre homens, mulheres, heterossexuais, homossexuais, transexuais e pessoas intersexuais, muitas vezes se traduzindo socialmente em discriminação e violência por conta da diferença em torno da sexuação, identidade sexual e práticas sexuais. A transexualidade - bem como a intersexualidade e a homossexualidade - para Lamas introduz uma dissonância entre o corpo, a identidade pessoal e o mandato cultural de gênero.

A simbolização da diferença anatômica "instituem códigos e prescrições culturais particulares para mulheres e homens" (p. 158), cis e trans*, uma vez que a partir do dado biológico é que as sociedades têm organizado a vida social com ideias de que há sentimentos, capacidade e condutas que correspondem aos sujeitos a partir de seus gêneros (LAMAS, 2014). Em outras palavras, gênero diz sobre atribuições, permissões e interdições dadas e reforçadas a determinados sujeitos a partir da cultura de uma sociedade. O gênero é uma construção histórica, geopolítica e uma expressão cultural. É por meio de uma lógica cultural do gênero que, por meio de um conjunto de práticas, ideias, discursos e representações sociais, se atribui a sujeitos que possuem certas características que são consideradas masculinas ou femininas elementos que influenciariam, (re)afirmariam e condicionariam sua conduta ao construir pautas de expectativas e crenças (LAMAS, 2014).

Ainda que a sociedade imponha acordos e práticas psicossociais coercitivas, enquanto ente/artefato simultaneamente físico e simbólico, o corpo experimenta "no sentido fenomenológico distintas sensações, prazeres, dores e pulsões" (p. 159). É neste sentido que Lamas aponta para os efeitos da presença de corpos que são ambíguos e os quais não são facilmente distinguíveis no binômio homem/mulher, provocando inquietude, rechaço e/ ou mal-estar. Para ela, além de ser construído socialmente e historicamente, o corpo possui uma psique cujos processos inconscientes não controla e assim a feminilidade e a masculinidade psíquicas muitas vezes transgridem os 
delineamentos culturais da socialização.

A ordem simbólica do gênero está tão profundamente arraigada nos moldes como a sociedade está constituída que não necessita justificativa, pois aparece como algo autoevidente a ponto de ser tomado como "natural” por conta de certas estruturas sociais, como a organização social no espaço-tempo e a divisão sexual do trabalho por um lado, e as estruturas cognitivas inscritas nos corpos e mentes por outro. É assim que as culturas consagram suas ordens simbólicas naturalizando-as impedindo a possibilidade de pensar sobre as relações de dominação de gênero, uma vez que se incorporam como esquemas inconscientes de percepção e apreciação das estruturas históricas de tais relações (LAMAS, 2014).

Ao compartilhar certos significados, as culturas de todas as sociedades, com suas linguagens e materializações da cultura, inculcam desde muito cedo a diferenciação sexual entre os sujeitos, mediante mandatos e acordos tácitos, por comportamentos e atitudes do que se entende como masculinidade aos machos humanos e da feminilidade às fêmeas humanas. $O$ corpo sexuado é como um dispositivo que articula o social e o psíquico nos seus jogos de "sexualidade e identidade, pulsão e cultura, carne e inconsciente" (p. 162).

Como seres bio-psico-sociais, os humanos introduzem identidades atípicas na ordem do normativo, no pensamento hegemônico em sua estrutura de coerção e de consentimento, justamente no que tange as dissidências sexuais. "O rechaço e a discriminação das identidades marginais ou não hegemônicas remetem a habitus seculares, produzidos por instituições de caráter patriarcal, que atropelam as disposições e o psiquismo e nutrem os estereótipos de gênero vigentes" (LAMAS, 2014, p. 163, tradução nossa).

São esses dispositivos que são bases discursivas que regulam disposições afetivas e éticas que geram ações de violência que são enquadradas seletiva e diferencialmente por questões de sexualidade e gênero que consideram as vidas trans* não como vidas, ou como vidas que não são passíveis de luto (BUTLER, 2015). É nesse sentido que numa perspectiva de entendimento de vivência de determinados sujeitos trans* que se encara a passabilidade e uma certa adequação às expectativas do gênero às quais se identificam como estratégia para lidar com um contexto de violência.

Para Anastacia, a passabilidade tem questões positivas e negativas que apontam para o paradoxo aqui apontado (invisibilizar as identidades trans* $\mathrm{X}$ promover segurança): 
a passabilidade sempre teve comigo uma relação de amor e ódio. Um lado de mim não tem a menor intenção de colocar isso como ponto importante na minha vida, porém, após me casar e, conviver com a família do meu marido, tive de me esforçar ao máximo para que a mesma não descobrisse minha realidade, por questão de sobrevivência (ANASTACIA, 2017, p.3).

A situação da não aceitação familiar e a transfobia disseminada em todos os campos da sociedade brasileira é que motivou o movimento de passar por cisgênera de Anastacia, inclusive a não inclusão de pessoas trans no mercado de trabalho: "meus pais me mandaram para fora de casa e a única oportunidade de não acabar na prostituição que eu tinha era aquela, me esconder atrás da aparência de cisgênera" (p.3).

Enquanto processo de passabilidade em ambientes digitais, estratégias de desindexação de conteúdos que se referem à condição do sujeito trans* antes dos processos de transição são uma alternativa possível de contribuição nesse processo. Viktor Mayer-Schönberger (2009) desenvolve a importância do esquecimento para o indivíduo e para a cultura e aborda a questão para as sociabilidades digitais. Para ele, abordarmos os desafios da lembrança digital nos lembra das mudanças que levaram ao desaparecimento do esquecimento: manter informações em nossas memórias digitais tornou-se o padrão de como operamos, como interagimos com nossas ferramentas técnicas e entre nós mesmos. Hoje, lembrar-se é tão presente em nossas sociabilidades digitais porque já não requer nem um ato consciencioso, perda de muito tempo, energia, ou dinheiro para acessar informações na memória digital. Ao pensarmos nas "memórias" sugeridas pelo Facebook, entendemos que parte desse processo de lembrança é automatizado pelo próprio sistema. Já o esquecimento digital, por outro lado, quando possível, exige grande esforço.

As memórias em seu aspecto digital possibilitam uma reconstrução abrangente de nossas palavras e ações mesmo que se tenha passado muito tempo. Elas não criam apenas uma versão espacial, mas também temporal do dispositivo conhecido como panóptico, restringindo nossa vontade de dizer o que queremos dizer e envolver na sociedade. O esquecimento desempenha um papel importante nos funcionamento na tomada de decisões humanas. Ele nos permite generalizar e resumir experiências individuais. Isso nos permite aceitar que os seres humanos mudem ao longo do tempo. Isso 
nos traz para o presente, em vez de nos manter atados permanentemente em um passado que se torna irrelevante (MAYER-SCHÖNBERGER, 2009).

Aqui neste artigo trabalhamos com o conceito de desindexação ao invés de tratar de esquecimento, por entender que esquecer articula uma série de fatores que estão para além das tecnologias de comunicação digital. O fenômeno sociotécnico que tratamos é, assim, mais específico e se refere à capacidade de desvincular determinado(s) dado(s) de certos motores de busca da Internet. Se entendermos que indexar é ordenar em forma de índice, ou seja, em uma tabela ou lista de coisas, pessoas ou informações classificadas por sua importância, no caso da Internet, desindexar é criar algum impedimento para que se vinculem dados a esse processo de elencar.

A indexação de conteúdo on-line se torna um problema devido à complexidade (de formatos e tipos) e quantidade dos dados presentes nos ambientes digitais e a necessidade de classificá-los e recuperá-los. Desse modo, os motores de busca leem os conteúdos da rede indexando-os automaticamente, classificando-os por relevância, usando como parâmetros análises dos links, acessos, termos, e outros (GALDO; VIEIRA; RODRIGUES, 2009). Esse processo vai vinculando uma série de dados e associando pessoas, territórios, imagens em diferentes tempos por critérios que a máquina considera de relevância. Assim, desindexar é romper com as ligações entre determinado dado com outros classificados e recuperados pela máquina, sendo que por dado podemos entender um agente humano.

No âmbito do Direito, Carlos Affonso Souza e Ronaldo Lemos (2016) afirmam que cresceu a discussão sobre o instituto do direito ao esquecimento o qual chamam de uma "espécie de tutela jurídica que concederia autorização para que as pessoas buscassem meios para que não se disponibilize ao público fatos indesejados" (p.123). Os autores ainda esclarecem que a tecnologia ainda não evoluiu a ponto de fazer com que uma pessoa seja forçada a esquecer determinado fato, portanto o que

se discute ao mencionar o direito ao esquecimento é a possibilidade de desindexar certos termos dos resultados de provedores de busca. Isso porque os provedores de busca são os meios utilizados para se localizar, na rede mundial de computadores, o conteúdo desejado e, portanto, a remoção desses resultados representaria efetiva barreira ao acesso de determinada informação (SOUZA; LEMOS, 2016, p. 123). 
No caso de sujeitos trans*, o direito a desindexação se emparelha com a questão da passabilidade quando o atual sujeito que se apresenta com determinado gênero quer se desassociar do seu passado qualquer dado que se refira aos momentos quando vivia com o gênero que lhe foi atribuído ao nascer e ao qual não se identifica.

Anastacia enquanto estratégia de desindexação mudou seu nome e sobrenome em perfis on-line,

para que ao pesquisarem no Google o meu sobrenome de batismo, mesmo relacionado ao meu nome social, não encontrassem nada relacionado ao meu passado. E-mails foram refeitos, contas no banco canceladas, sites desativados, fotos de infância/pré-transição queimadas e deletadas de qualquer mídia que encontrei na casa da minha família, e tudo que até hoje tem estado ao meu alcance faço para impedir que descubram meu passado. Infelizmente, o processo de mudança do nome de registro ainda tramita no fórum. O ganho é muito óbvio: uma vida normal, como sempre quis, uma mulher comum, com um passado comum, de aparência comum. Porém perdi no processo anos de conteúdo gerado na internet, artigos científicos publicados, amizades e boas memórias (ANASTACIA, 2017, p. 2).

A observação do caso de Anastasia nos faz conjecturar que em relação à passabilidade, aparece fortemente a figura da família como o lugar fonte de informação e descoberta sobre um passado anterior a transição ao qual se quer esconder. A família aparece como chave de descoberta e ao mesmo tempo lugar da punição, ligada à expulsão e ao ser lançada à prostituição, destino comum de muitas mulheres trans que não encontram outras oportunidades de trabalho. Também é notável a performance do papel de muIher cis como lugar do esconderijo. Sobre os objetos para manejar os dados sobre seu passado - e no caso específico de desindexar o passado pré-transição - vemos alguns atores elencados ligados ao nome, fotos e dados em sites e instituições bancárias. A justiça como lugar da mudança de nome, o motor de busca do Google como lugar de pesquisa e possibilidade de descoberta do nome de batismo e ainda um esforço da interlocutora para impedir que se associe novamente a esse nome. Vemos ainda a necessidade de mudança de nome em e-mail pessoal. As fotos do passado aparecem ligadas 
também a família e a elas estão associadas ações de apagar e queimar. A necessidade de cancelamento de contas de banco e de sites também está associada.

Se por um lado as plataformas digitais criam lugares seguros que são propícios a trocas de experiências vividas pelos corpos trans e enredamentos que permitem a criação de saberes, por outro, mesmo que tecnicamente exista a possibilidade de desindexação de certos conteúdos, parte deles, por estarem em caráter de copropriedade, são um empecilho para alguns sujeitos que gostariam de se livrar de parte do conteúdo on-line sobre suas vidas pré-transição. Performances de passabilidade enquanto processo de dissimulação da condição trans do sujeito em certos contextos sociais se configuram como estratégias de sobrevivência ao rechaço e à discriminação em sociedades transfóbicas. As relações que acontecem em ambientes digitais apresentam pouca possibilidade de controle de audiência e de se desindexar dados dos resultados de provedores de busca e de redes sociais on-line. Assim as potências trazidas por essas tecnologias induzem a uma relação ética entre os coproprietários da informação em processos de cogestão dos limites da privacidade de cada sujeito.

As ações de Anastacia dizem sobre algumas das possibilidades do gerenciamento de impressões e manejo dos próprios dados na rede. Em geral, os benefícios da digitalização de si nas redes sociais são o fato de permitir que os usuários se envolvam na distribuição de conteúdo, compartilhamento e consumo em um custo e em menos tempo do que seria de outra forma possível sem tecnologia. A digitalização de si nas redes sociais aumenta a visibilidade das divulgações e diminuem os esforços para localizar informações, como no caso citado das comunidades formadas nessas redes. Essas exposições são arquivadas e permanecem pesquisáveis muito depois de serem postadas. Nelas ainda os usuários podem elaborar as divulgações, elaborando e editando mensagens antes e depois de publicá-las e a informação divulgada está associada tanto à divulgador quanto a pessoa a que se dirige (VITAK; KIM, 2014).

A fronteira borrada entre público e privado e o fato dos usuários deixarem de reconhecer a audiência total de seus dados são preocupações com privacidade que podem servir de obstáculo ao envolvimento de digitalização de si por sujeitos trans*. Como estratégias individuais, podemos citar o que o Facebook oferece de configuração de privacidade para ajudar os usuários a se envolverem na regulação de limites sobre suas publicações, 
podendo, por exemplo, limitar o acesso a cada conteúdo que eles compartiIham no site configurando-o para ser visível para um conjunto de amigos ou, inversamente, para que esteja escondido de um subconjunto de sua rede de amigos (VITAK; KIM, 2014). É um tipo de estratégia preventiva que reproduz alguns dos limites dos ambientes off-line, algumas informações sobre si e sobre o corpo dos sujeitos trans* só é interessante para eles serem compartilhadas com certa audiência e não com outras que eventualmente convivem naquela rede.

Outra estratégia preventiva é a autocensura que envolve o controle do conteúdo da informação divulgada. Assim como Anastacia fez com parte de seu conteúdo, é a possibilidade de editar e de excluir dados sobre si. Há ainda a possibilidade de gerenciamento de conteúdo que envolve uma forma de escrita muito própria que esconde o verdadeiro significado de uma mensagem de conteúdo que apenas parte da rede entende. Por fim, existe o controle de acesso no nível da conta, no sentido de bloquear alguns usuários indesejados, impedindo tecnicamente que tenham acesso a suas contas (VITAK; KIM, 2014).

A privacidade em rede invoca a constelação de dinâmicas de audiência, normas sociais e funcionalidade técnica que afeta os processos de divulgação, ocultação, dissimulação e interpretação de informações em um público em rede (BOYD, 2011). Se entendemos a privacidade como a gestão de fronteiras entre os sujeitos, àquilo que permitimos que o outro saiba ou não enquanto uma negociação sempre em processo, temos que dar conta também que a copropriedade desses dados on-line não permite que apenas estratégias individuais deem conta de um manejo dessas informações, especialmente no que tange a questão da passabilidade. A passabilidade em rede como seus aspectos inerentes com a privacidade individual não pode ser alcançada simplesmente fornecendo ou negando informações, pois ela requer um controle significativo sobre os contextos em rede nos quais a informação flui.

No nível da tecnologia dos sistemas e das legislações sobre ela poderia se conceber, como outra maneira possível de facilitar processos de desindexação, a possibilidade de associar às informações que armazenamos em memórias digitais datas de validade que seriam definidas pelos usuários. Assim, nos armazenamentos digitais, os dispositivos seriam programados para excluir automaticamente as informações que atingissem ou excedessem o prazo de validade (MAYER-SCHÖNBERGER, 2009). 
Alcançar a passabilidade on-line exige que as pessoas tenham uma compreensão e influencia na definição do contexto em que a informação está sendo interpretada. Isso pode ser feito pela coconstrução da arquitetura dos sistemas, ou pode ser feito incorporando significado e contexto no próprio conteúdo. Em última análise, as tentativas de navegar a privacidade através das mídias sociais revelam a subjacente dinâmica interacional das práticas de privacidade, demonstrando que o modelo individualista de privacidade não mapeia com precisão o ambiente digital em que socializamos. As pessoas vivem em contextos sociais, seus atos públicos em rede se implicam mutuamente. Reconhecer que a privacidade está em rede sugere que ela pode ser melhorada através de normas sociais compartilhadas sobre o compartilhamento de informações (MARWICK; BOYD, 2014).

\section{CONSIDERAÇÕES}

Em nossa conversa Anastacia afirmou que o contato com uma comunidade virtual on-line em plataformas de rede social, inicialmente no Orkut e posteriormente no Facebook, foi para ela "uma oportunidade de finalmente ser "normal", uma mulher comum" (ANASTACIA, 2017, p.1). Essa comunidade em que pessoas trans* discutiam sobre o uso de hormônios e seus efeitos foi um lugar de segurança para se obter informações sobre tornar-se o que se sente ser. Além disso, a necessidade de "desaparecer" por um tempo, mudar-se, se desindexar nas plataformas de redes sociais e dos resultados dos motores de busca elementos do passado de quando vivia com o gênero ao qual foi identificada ao nascer e que não mais correspondia ao que desejava ser lida foram estratégias para a constituição de um estatuto de passabilidade cisgênera.

Conclui-se, assim, que as plataformas digitais criam lugares seguros que são propícios a trocas de experiências vividas pelos corpos trans* e enredamentos que permitem a criação de saberes. No entanto, mesmo que tecnicamente exista a possibilidade de desindexação de certos conteúdos, parte deles, por estarem em caráter de copropriedade, são um empecilho para alguns sujeitos que gostariam de se livrar de parte do conteúdo on-line sobre suas vidas pré-transição. Performances de passabilidade enquanto processo de dissimulação da condição trans* do sujeito em certos contextos sociais se configuram como estratégias de sobrevivência ao rechaço e à discriminação em sociedades transfóbicas. Ao mesmo tempo tal processo aponta para a característica performática do gênero, inclusive, tanto quanto outras pos- 
sibilidades de configuração de gênero, da própria heterossexualidade que é reiterada socialmente e expõe seu caráter de construção social. As relações que acontecem em ambientes digitais apresentam pouca possibilidade de controle de audiência e de se desindexar dados dos resultados de provedores de busca e de redes sociais on-line. Gerenciar os limites das informações privadas sobre si é manejar, na medida do possível, seus rastros digitais e suas performances sociais em ambientes digitais, que sem presença física dos corpos é mediada e permanece. Assim as potências trazidas por essas tecnologias induzem a uma relação ética entre os coproprietários da informação em processos de cogestão dos limites da privacidade de cada sujeito.

\section{REFERÊNCIAS}

ANASTACIA. Entrevista com Anastacia sobre Passabilidade e Internet. [Entrevista concedida a] Sérgio Rodrigo da Silva Ferreira. Dados de pesquisa, Salvador, 6 set. 2017.

BOYD, D.. Social Network Sites as Networked Publics: Affordances, Dynamics, and Implications. In: PAPACHARISSI, Z. (org.). A Networked Self: Identity, community and culture on social network sites. New York: Routledge, 2011. p. 39-58.

BUTLER, J.. Quadros de Guerra: quando a vida é passível de luto? Rio de Janeiro: Civilização Brasileira, 2015.

DERLEGA, V. J.; CHAIKIN, A. L. Privacy and Self-Disclosure in Social Relationships. Journal of Social Issues, 33(3), 102-115. 1977.

DUQUE, T. Gêneros Incríveis: um estudo sócio-antropológico sobre as experiências de (não) passar por homem e/ou mulher. Campo Grande: Editora UFMS, 2017.

FERREIRA, S. R. S.. O Direito ao Manejo dos Próprios Dados, a Autodeterminação e a Passabilidade Trans: diálogos a partir de um relato. In: Seminário Internacional Enlaçando Sexualidades, 2017, Salvador. Anais do Enlaçando, 2017. v. 1. p. 1-11.

FERREIRA, S. R. S.; NATANSOHN, L. G. . Digitalização de Si: algumas contribuições teóricas para entender o corpo em ambientes digitais. In: Congresso Internacional em Humanidades Digitais, 2018, Rio de Janeiro. Anais do Congresso Internacional em Humanidades Digitais. Rio de Janeiro: CPDOC/FGV, 2018. v. 1. p. 35-41.

GALDO, A.; VIEIRA, A. F. G.; RODRIGUES. R. S..Classificação Social da Informação na Web: Tecnologia, Informação e Gente. DataGramaZero - Revista de Ciência da Informação, v.10, n.8, dez. 2009

HARAWAY, D. Saberes Localizados: a questão da ciência para o feminismo e o privilégio da perspectiva parcial. Cadernos Pagu (5). Campinas: Núcleo de Estudos de Gênero - Pagu/ Unicamp, 1995, p.7-41.

KAAS, H. Trans* como termo guarda-chuva | Transfeminismo. Disponível em: <https:// transfeminismo.com/trans-umbrella-term/>. Acesso em: 1 fev. 2019.

LAMAS, M. Cuerpo, Sexo y Política. México DF: Ed. Océano, 2014. 
MARWICK, A. E.; BOYD, D.. Networked privacy: How teenagers negotiate context in social media. New Media \& Society, 2014.

MAYER-SCHÖNBERGER, V.. Delete: The Virtue of Forgetting in the Digital Age. Nova Jersey: Princeton University Press, 2009.

PETRONIO, S. S. Boundaries of privacy: dialectics of disclosure. Albany: State University of New York Press, 2002.

PLATERO, R. (Lucas). Trans*exualidades: acompañamiento, factores de salud y recursos educativos. Barcelona: Ediciones Bellaterra, 2014.

REDE NACIONAL DE PESSOAS TRANS DO BRASIL (REDE TRANS BRASIL). Diálogos Sobre Viver Trans - Monitoramento: Assassinatos e Violação de Direitos Humanos de Pessoas Trans no Brasil - Dossiê, 2018. Disponível em < http://redetransbrasil.org.br/wp-content/ uploads/2019/01/Dossi\%C3\%AA-Rede-Trans-Brasil-2018-Portugu\%C3\%AAs.pdf >. Acesso em 31 jan. 2019.

STONE, S. El imperio contraataca. Um manifesto postransexual. In: GOLOFRE, P.; MISSÉ, M. (org.). Políticas Trans: una antología de textos desde los estudios trans norteamericanos. Barcelona - Madrid: Editorial Egales, 2015.

STRYKER, S. Prólogo. In: GOLOFRE, P.; MISSÉ, M. (org.). Políticas Trans: una antología de textos desde los estudios trans norteamericanos. Barcelona - Madrid: Editorial Egales, 2015.

VITAK, J.; KIM, J.. "You Can'T Block People Offline”: Examining How Facebook's Affordances Shape the Disclosure Process. Proceedings of the 17th ACM Conference on Computer Supported Cooperative Work \& Social Computing. Nova York: ACM, 2014. 


\section{Sérgio Rodrigo da Silva Ferreira}

É doutorando em Comunicação e Cultura Contemporâneas pela Universidade Federal da Bahia, membro do Grupo de Estudo em Gênero, Tecnologias Digitais e Cultura (GIG@) e bolsista FAPESB. É mestre em Psicologia e em Comunicação e Territorialidades e graduado em Comunicação Social com habilitação em Jornalismo todos pela Universidade Federal do Espírito Santo.

E-mail: sergiorodrigosf@gmail.com

\section{Leonor Graciela Natansohn}

É Professora Associada da Faculdade de Comunicação da Universidade Federal da Bahia e docente do Programa de Pós-Graduação em Comunicação e Cultura Contemporâneas. Coordena o Grupo de Estudo em Gênero, Tecnologias Digitais e Cultura (GIG@). É Doutora (2003) em Comunicação e Cultura Contemporâneas pela Universidade Federal da Bahia e Pós-doutora pela Universidad Nacional de Buenos Aires (Argentina). É orientadora deste projeto de pesquisa. E-mail: graciela71@gmail.com 